\title{
USING A NOVEL METHOD TO EVALUATE THE PERFORMANCE OF HUMAN RESOURCES IN GREEN LOGISTICS ENTERPRISES
}

\author{
NOWA METODA OCENY WYDAJNOŚCI ZASOBÓW LUDZKICH \\ W ZIELONYCH PRZEDSIĘBIORSTWACH LOGISTYCZNYCH
}

\begin{abstract}
The essence of low-carbon logistics is to make logistics capacity grow moderately to meet the requirements of social and economic developments and the goals of energy conservation and carbon reduction through logistics planning and policies, logistics rationalization and standardization, logistics informationization, low-carbon logistics technologies, etc. This study evaluates the performances of human resources in low-carbon logistics enterprises from three assessment facets: work ability, work performance, and work attitude. It adopts the AHP method to reasonably determine an indicator system of performance evaluation and its weight to avoid certain human-caused bias. According to the results herein, the low-carbon work attitude of the case company in recent years has produced good performance, but its low-carbon work performance and low-carbon work ability are both poor. The case company should practically implement and strengthen these indicators so as to enhance human resource performance in low-carbon logistics enterprises. This study establishes a human resources performance evaluation system for low-carbon logistics enterprises to measure the low-carbon working ability, work performance, and working attitude of their general staff. In this way, enterprises may understand their development status, improve development plans, and formulate the best human resources management and development decisions, thus positively guiding their future development.
\end{abstract}

Keywords: low-carbon, environmental management, sustainable development, green enterprise

\section{Introduction}

In the context of global warming, low-carbon economies based on low energy consumption, low pollution, and low emissions have become global hot spots. Countries all over the world have put forward the concepts of environmental protection as well as green and low-carbon energies, with many promising to reduce their carbon emissions. In this context, low-carbon logistics is also of great concern. In terms of the energy-intensive logistics industry, great attention should be paid to low-carbon logistics by both countries and enterprises. For enterprises, low-carbon consumption will be a new opportunity for development, and responsibility towards it should also be undertaken by logistics companies globally [1].

\footnotetext{
${ }^{1}$ Zhongshan Institute, University of Electronic Science and Technology of China, Guangdong 528400, China

${ }^{2}$ College of Business Administration, Capital University of Economics and Business, Beijing 100070, China

*Corresponding author: wangkai@cueb.edu.cn
} 
In line with the requirements of the new era of low-carbon economies, low-carbon logistics may effectively address severe social energy consumption and global warming in a bid to achieve sustainable development [2]. The essence of low-carbon logistics is to make logistics capacity grow moderately to meet the requirements of social and economic developments and to ease energy supply pressure through logistics planning and policies, logistics rationalization and standardization, logistics informationization, and low-carbon logistics technologies [3].

Low-carbon logistics are still plagued by multiple problems at present. This has prompted governments of all countries to take measures as soon as possible to improve the status of low-carbon logistics, stimulate technological innovation, change consumption ideas of consumers and stimulate their motivation. Relevant studies deem that governments of all countries should execute the following [4, 5]:

(1) Include the development of low-carbon logistics in policies and regulations

Governments should explicitly include low-carbon logistics in their development plans and simultaneously conduct specialized research on low-carbon logistics systems. In particular, cities with relatively developed logistics industries should focus on setting up a low-carbon logistics system in low-carbon urban construction and low carbon economic development.

(2) Encourage the promotion of low-carbon logistics technology

Governments should encourage and promote the technical application of various links within the low-carbon logistics system. They should also encourage research institutes to cooperate with global leading logistics enterprises, set up relevant laboratories, and carry out simulation and technical tests on indicator systems of the performance assessment of low-carbon logistics.

(3) Train related personnel

Governments should vigorously step up their training in the field of low-carbon logistics so as to attract a large number of talents to invest in this area, with the result that low-carbon logistics can develop and maintain its vitality.

(4) Strengthen the promotion of low-carbon logistics

Only propaganda of low-carbon logistics may contribute to changing the consumption concepts of consumers and lead to a shift in their behaviors so that enterprises can obtain benefits in low-carbon logistics. This should further encourage enterprises to make investments in low-carbon logistics for technological innovation and applications, forming a positive virtuous circle.

Human resources are an important part of the great competition in the logistics market and significantly affect the operations of enterprises. Performance evaluations of human resources are particularly important for low-carbon logistics enterprises with scarce talents [6]. Such evaluations in these enterprises are of great significance for their strategic development.

This study establishes a human resource performance evaluation system for low-carbon logistics enterprises to measure the low-carbon working ability, work performance, and working attitude of their general staff. In this way, enterprises may understand their development status and improve their development plans to formulate the best human resources management and development decisions, thus helping guide their future development. 


\section{Literature review}

\section{Low-carbon logistics}

In 2008, the European Renewable Energy Council (EREC) defined low-carbon living as a low-carbon alternative to fossil fuels on the basis of ensuring economic growth and improving people's welfare [3]. With the continuous development of society, a low-carbon philosophy can also be constantly enriched. In other words, a low-carbon economy refers to a form of economic development where the consumption of high-carbon energy such as coal and oil is minimized and greenhouse gas emissions such as carbon dioxide are reduced through changes in the energy structures by means of industrial restructuring, technological innovation, and new energy development. The goal is to achieve a win-win situation of economic and social developments as well as ecological environmental protection [6].

Low-carbon logistics is characterized by the following five aspects [7, 8]: (1) Systematicness. The system is made up of several different elements in order to realize its intended purpose. These elements interact with each other to form an organic whole. In this regard, low-carbon logistics is a complete system composed of a set of functional elements aimed at reducing current energy consumption. (2) Bidirectionality. Two-way flow is an indispensable feature of completely mobilized logistics. Bidirectional low-carbon logistics denotes both forward and reverse low-carbon logistics. (3) Multi-purpose. The ultimate goal of low-carbon logistics is to use low-carbon ideas to reform existing industries and to achieve sustainable development. To reach this end, the logistics system should organically combine the economy, consumers, society, and ecological environment to achieve a balance of interests. These four points exhibit mutual restraint and conflict in the system. (4) Uniform standard. Low-carbon logistics develops different standards in different logistics control points to coordinate and improve management of the logistics system. This in turn enables low-carbon logistics to develop uniform standards at higher management and technical levels for the technologies used, emerging energy, and carbon reduction. (5) Advanced technology. Realization of low-carbon logistics mainly depends on the practical application of advanced technology. Environmental-oriented low-carbon logistics focuses on the development and application of advanced technologies. Without advanced technologies, it is hard to achieve low-carbon logistics. These technologies may serve as ideas or devices.

\section{Performance evaluation of human resources in low-carbon logistics enterprises}

Employee performance evaluation is a formal assessment system of job performance that measures employees' job behavior and outcomes through systematic approaches and principles. Performance evaluation is the communication between managers and employees, and the outcomes can directly affect numerous employee benefits such as pay raises, bonuses, promotion, and demotion. Performance evaluation is key to organizational development. A structured performance evaluation system emphasizes the contributing indicators while discarding those irrelevant to organizational development [9-11].

Generally, employee performance can be assessed in dimensions such as organizational commitment, job capacity, job performance, job attitude, and employee growth. Commonly used performance evaluation methods are divided into results-oriented and behavior-oriented methods. For example, the results-oriented methods include rating scales, management by objectives, and key performance indicators, whereas behavior-orientated methods include the critical incident technique, behavior observation 
scales, behaviorally anchored rating scales, and 360 degree feedback. Additionally, performance evaluation methods exist that focus on employees' traits (e.g., a graphic rating scale) $[12,13]$.

Talented people are not only the main body of labor for enterprises, but are also a scarce resource for enterprises. Under the development trend of low-carbon economies, the scarcity of human resources stands out. In terms of the average enterprises, the following four aspects characterize human resources of low-carbon logistics enterprises:

\section{(1) Low-carbon technology}

Logistics systems in enterprises can be divided into purchasing system, operating system, sales system, recycling system, and information system, which include transportation, warehousing, distribution, loading and unloading, and packaging [8,9]. The best route should be designed with Internet technology during transportation, while the optimization theory should be adopted to determine the optimal inventory for warehousing. As all subsystems of the logistics system should be supported by low-carbon technologies, human resources must come equipped with certain low-carbon technologies.

\section{(2) Low-carbon concept}

Logistics systems should be continuously improved, and their development should take into account the current environment and resources, which can help form a logistics system that promotes the healthy development of the economy and consumption market. Low-carbon logistics is a new trend in the logistics industry, and the low-carbon concept is an essential part of work skills among its human resources. The green low-carbon approach can achieve the goal of environmental protection while obtaining economic benefits [14].

\section{(3) Global strategic vision}

The entire supply chain instead of a single logistics company will dominate the future of low-carbon logistics. The concept involves a series of links encompassing raw material procurement, product manufacturing, transportation, and product packaging. The integration of low carbon into the entire supply chain will generate a two-pronged effect. To cater to the trend of low-carbon development, enterprises should input a large amount of capital. In this regard, enterprises' human resources should take on a global strategic vision in order to convert input into larger output and to form their core competitiveness [12].

\section{(4) Innovation awareness}

As enterprises develop via market competition, such competition among knowledgeintensive and talent-intensive low-carbon logistics enterprises tend to turn into competition for talented people. Creating new technologies or innovating the use of existing technologies is the driving force for the sustainable development of low-carbon logistics enterprises [13, 14].

This study establishes a human resource performance evaluation system along with the AHP method for low-carbon logistics enterprises to measure the low-carbon working ability and work performance of their general staff. This study also adopts the AHP method to reasonably determine an indicator system of performance evaluation and its weight to avoid certain human-caused bias. 


\section{Research method}

\section{Construction of AHP indicator system}

This study focuses on the performance evaluation of human resources of low-carbon logistics enterprises. According to the introduction and literature discussion above, this study takes work ability, work performance, and work attitude as the three facets of the evaluation system.

The establishment of the indicator system follows the principle of hierarchy. First, the performance evaluation indicators of human resources of low-carbon logistics are divided into three facets as first-level indicators: work ability, work performance, and work attitude. Each facet can be subdivided into second-level indicators. The second-level indicator of work ability is subdivided into low-carbon expertise, low-carbon professional skills, and low-carbon innovation potential; the second-level indicator of work performance is subdivided into quantity of completed low-carbon tasks, quality of completed low-carbon tasks, and efficiency of completed low-carbon tasks; the second-level indicator of work attitude can be broken down into low-carbon discipline, low-carbon collaboration, and low-carbon enthusiasm. Table 1 shows the specific details.

Performance evaluation system of human resources

Table 1

\begin{tabular}{|c|c|c|c|}
\hline First-level evaluation indicators & Weights & Second-level evaluation indicators & Weights \\
\hline \multirow{3}{*}{$\mathrm{A}_{1}$ workability } & \multirow{3}{*}{$\mathrm{W} 1$} & $\mathrm{~A}_{11}$ low-carbon expertise & $\mathrm{W} 11$ \\
\cline { 3 - 4 } & & $\mathrm{A}_{12}$ low-carbon professional skills & $\mathrm{W} 12$ \\
\cline { 3 - 4 } & \multirow{3}{*}{$\mathrm{W} 2$} & $\mathrm{~A}_{13}$ low-carbon innovation potential & $\mathrm{W} 13$ \\
\cline { 3 - 4 } & & $\mathrm{A}_{21}$ quantity of completed low-carbon tasks & $\mathrm{W} 21$ \\
\cline { 3 - 4 } $\mathrm{A}_{2}$ work performance & $\mathrm{A}_{22}$ quality of completed low-carbon tasks & $\mathrm{W} 22$ \\
\cline { 3 - 4 } & \multirow{3}{*}{$\mathrm{A}_{3}$ work attitude } & $\mathrm{A}_{23}$ efficiency of completed low-carbon tasks & $\mathrm{W} 23$ \\
\hline & \multirow{2}{*}{$\mathrm{W} 3$} & $\mathrm{~A}_{31}$ low-carbon discipline & $\mathrm{W} 31$ \\
\cline { 3 - 4 } & & $\mathrm{A}_{32}$ low-carbon collaboration & $\mathrm{W} 32$ \\
\cline { 3 - 4 } & & $\mathrm{A}_{33}$ low-carbon enthusiasm & $\mathrm{W} 33$ \\
\hline
\end{tabular}

\section{Theory of the AHP method}

Analytic Hierarchy Process (AHP) is a theory developed by Thomas L. Saaty in 1971. It is mainly applied in uncertain circumstances and decision-making issues with multiple evaluation criteria. In terms of decision-making, the hierarchical structure helps to understand things, but when faced with the choice of an appropriate option, the alternatives must be evaluated against certain benchmarks to determine the priorities of these alternatives and to find the appropriate answer [15-17]. Through group discussions, AHP pools the opinions of scholars and experts involved in policy-making at all levels. By simplifying the complex problem evaluation system into a concise elemental hierarchy system, AHP uses a nominal scale to conduct a pairwise comparison of elements in each level so as to establish a pairwise comparison matrix, and then the eigenvector of such matrix can be obtained. The eigenvectors of the matrix are used as the priority vectors of the hierarchy to represent the priorities among the elements, and the maximized eigenvector is adopted to compare the strength of consistency of such a matrix to provide a reference for decision makers [18-20].

AHP first lists all the relevant factors in the decision-making problem and then establishes an inter-related hierarchical structure [21-23]. Hierarchical analysis adopts the 
layer of factors above each level as the basis of evaluation for the next level - that is, any two factors of a certain level will serve as the criterion of the above level. The relative contribution or importance of these two factors will be evaluated (that is, the relative weight value) [24-26]. In this process of comparison between each two factors, the complicated problems will be decomposed into pairs of comparisons, so that evaluators, when facing multiple factors, can focus on the important relationship between each two factors [27, 28]: AHP has the following assumptions during the whole progress [29, 30].

(1) A system or question can be broken down into multiple categories or components that are compared to form a hierarchical structure of directional networks.

(2) In the hierarchical structure, the elements of each level are assumed to be independent. Certain or all elements in the above level may be used as a benchmark for comparison.

(3) When comparing, the absolute value scale can be converted to a ratio scale.

(4) The reciprocal of the matrix after pairwise comparison is symmetrical to the main diagonal and can be processed by the positive reciprocal matrix.

(5) Preference relations satisfy transitivity, but a complete transference is not easy. Hence, the non-transitive nature is allowed, but the degree of consistency must be tested.

(6) Proportion of superiority of factors should be obtained through the weighting principle.

(7) As long as any element appears in the hierarchical structure, regardless of its proportion, it is considered to be related to the entire target structure of evaluation.

\section{Results and discussion}

\section{Establishment of performance evaluation system of human resources}

Company A is currently one of the top ten logistics companies in Zhongshan, China. In recent years, Company $\mathrm{A}$ has been committed to the development of low-carbon logistics and achieved certain results. Company A would like to know about the utilization of its own low-carbon human resources and to find out whether there is still room for growth in the company's performance on low-carbon human resources. This study takes this case company as an example to establish a performance evaluation system of human resources in low carbon logistics enterprises.

This study sent out by post a total of 20 questionnaires to 10 professors, 7 corporate executives, and 3 related government officials, using a 9-point scale for pair comparison with a maximum of 9 points and a minimum of 1 point. The whole questionnaire process lasted from August 15, 2017 to September 15, 2017, and all 20 valid questionnaires were collected.

\section{Calculation results}

\section{Calculation of indicator weights}

(a) Calculation of second-level indicator weights

The second-level analysis indicators include $\mathrm{A}_{1}$ work ability, $\mathrm{A}_{2}$ work performance, and $\mathrm{A}_{3}$ work attitude. The average score of 20 experts is rounded to the nearest whole number. The original scores are shown in Table 2.

The paired comparison matrix yielded a C.I. value of 0.08 , or less than the standard value of 0.1 , indicating that the second-level pairwise comparison is consistent. The weights and rankings of each indicator are shown in Table 3. 
Original scores of indicators in the second level

\begin{tabular}{|c|c|c|c|}
\hline Evaluation indicators & Workability & Work performance & Work attitude \\
\hline Workability & 1 & 6 & 4 \\
\hline Work performance & & 1 & 6 \\
\hline Work attitude & & & 1 \\
\hline
\end{tabular}

Weight table of the second level

\begin{tabular}{|c|c|c|}
\hline Evaluation indicators & Weights & Order \\
\hline $\mathrm{A}_{1}$ workability & 0.21 & 2 \\
\hline $\mathrm{A}_{2}$ work performance & 0.69 & 1 \\
\hline $\mathrm{A}_{3}$ work attitude & 0.10 & 3 \\
\hline
\end{tabular}

Table 3 presents that "work performance" in the second level has the highest weight in the human resources performance evaluation of low-carbon logistics enterprises, followed by "work ability" and "work attitude" at respectively $0.69,0.21$, and 0.10 . This study shows that "work performance" accounts for the largest proportion of human resources performance evaluation in low-carbon logistics enterprises and has the biggest impact.

(b) Calculation of the third-level indicator weights

The average score of 20 experts is rounded to the nearest whole number. The original scores are shown in Tables 4, 5 and 6.

Original scores of $\mathrm{A}_{1}$ work ability indicator

\begin{tabular}{|c|c|c|c|}
\hline Evaluation indicators & Low carbon expertise & $\begin{array}{c}\text { Low carbon } \\
\text { professional skills }\end{array}$ & $\begin{array}{c}\text { Low-carbon innovation } \\
\text { potential }\end{array}$ \\
\hline Low-carbon expertise & 1 & 6 & 4 \\
\hline $\begin{array}{c}\text { Low-carbon professional } \\
\text { skills }\end{array}$ & & 1 & 7 \\
\hline $\begin{array}{c}\text { Low-carbon innovation } \\
\text { potential }\end{array}$ & & & 1 \\
\hline
\end{tabular}

Original scores of $\mathrm{A}_{2}$ work performance indicator

\begin{tabular}{|c|c|c|c|}
\hline Evaluation indicators & $\begin{array}{c}\text { Quantity of completed } \\
\text { low-carbon tasks }\end{array}$ & $\begin{array}{c}\text { Quality of completed } \\
\text { low-carbon tasks }\end{array}$ & $\begin{array}{c}\text { Efficiency of completed } \\
\text { low-carbon tasks }\end{array}$ \\
\hline $\begin{array}{c}\text { Quantity of completed } \\
\text { low-carbon tasks }\end{array}$ & 1 & 7 & 4 \\
\hline $\begin{array}{c}\text { Quality of completed } \\
\text { low-carbon tasks }\end{array}$ & 1 & 6 \\
\hline $\begin{array}{c}\text { Efficiency of completed } \\
\text { low-carbon tasks }\end{array}$ & & & 1 \\
\hline
\end{tabular}

Original scores of $\mathrm{A}_{3}$ work attitude indicator

\begin{tabular}{|c|c|c|c|}
\hline Evaluation indicators & Low-carbon discipline & $\begin{array}{c}\text { Low-carbon } \\
\text { collaboration }\end{array}$ & $\begin{array}{c}\text { Low-carbon } \\
\text { enthusiasm }\end{array}$ \\
\hline Low-carbon discipline & 1 & 3 & 2 \\
\hline $\begin{array}{c}\text { Low-carbon } \\
\text { collaboration }\end{array}$ & & 1 & 3 \\
\hline Low-carbon enthusiasm & & & 1 \\
\hline
\end{tabular}


The second-level evaluation indicator of $A_{1}$ work ability is divided into: $A_{11}$ low-carbon expertise, $\mathrm{A}_{12}$ low-carbon professional skills, and $\mathrm{A}_{13}$ low-carbon innovation potential, with respective weights of $0.19,0.71$, and 0.10 . In addition, the paired comparison matrix yielded a C.I. value of 0.08 , or less than the standard value of 0.1 , indicating that the pairwise comparison is consistent. Please refer to (Table 7).

The second-level evaluation indicator of $A_{2}$ work performance is divided into: $A_{21}$ quantity of completed low-carbon tasks, $\mathrm{A}_{22}$ quality of completed low-carbon tasks, and $\mathrm{A}_{23}$ efficiency of completed low-carbon tasks, with respective weights of $0.25,0.62$, and 0.13 . In addition, the paired comparison matrix yielded a C.I. value of 0.07 , or below the standard value of 0.1 , indicating that the pairwise comparison is consistent. Please refer to (Table 8).

The second-level evaluation indicator of $A_{3}$ work attitude is divided into: $A_{31}$ low-carbon discipline, $\mathrm{A}_{32}$ low-carbon collaboration, and $\mathrm{A}_{33}$ low-carbon enthusiasm, with respective weights of $0.10,0.70$, and 0.20 . In addition, the paired comparison matrix yielded a C.I. value of 0.09 , or lower than the standard value of 0.1 , indicating that the pairwise comparison is consistent. Please refer to (Table 9).

Table 7

Weight table of $\mathrm{A}_{1}$ work ability of the third level

\begin{tabular}{|c|c|c|}
\hline Evaluation indicators & Weights & Order \\
\hline $\mathrm{A}_{11}$ low-carbon expertise & 0.19 & 2 \\
\hline $\mathrm{A}_{12}$ low-carbon professional skills & 0.71 & 1 \\
\hline $\mathrm{A}_{13}$ low-carbon innovation potential & 0.10 & 3 \\
\hline
\end{tabular}

Table 8

Weight table of $\mathrm{A}_{2}$ work performance of the third level

\begin{tabular}{|c|c|c|}
\hline Evaluation indicators & Weights & Order \\
\hline $\mathrm{A}_{21}$ quantity of completed low-carbon tasks & 0.25 & 2 \\
\hline $\mathrm{A}_{22}$ quality of completed low-carbon tasks & 0.62 & 1 \\
\hline $\mathrm{A}_{23}$ efficiency of completed low-carbon tasks & 0.13 & 3 \\
\hline
\end{tabular}

Table 9

Weight table of $A_{3}$ work attitude of the third level

\begin{tabular}{|c|c|c|}
\hline Evaluation indicators & Weights & Order \\
\hline $\mathrm{A}_{31}$ low-carbon discipline & 0.10 & 2 \\
\hline $\mathrm{A}_{32}$ low-carbon collaboration & 0.70 & 1 \\
\hline $\mathrm{A}_{33}$ low-carbon enthusiasm & 0.20 & 3 \\
\hline
\end{tabular}

(c) Overall weights

According to the calculation results of weights of the second and third levels, this study summarizes the total weights and rankings of performance evaluation indicators of human resources at all levels in low-carbon logistics enterprises (Table 10).

This study shows that the top five key evaluation indicators affecting human resources performance of low-carbon logistics enterprises are " $\mathrm{A}_{22}$ quality of completed low-carbon tasks", "A $\mathrm{A}_{21}$ quantity of completed low-carbon tasks", "A $\mathrm{A}_{12}$ low-carbon professional skills", " $\mathrm{A}_{23}$ efficiency of completed low-carbon tasks", and "A $\mathrm{A}_{32}$ low-carbon collaboration". 
Weights of performance evaluation indicators of human resources in low-carbon logistics enterprises

\begin{tabular}{|c|c|c|c|}
\hline Dimensions/Criteria & Local Weight & Global Weight & Order \\
\hline $\mathrm{A}_{1}$ workability & 0.21 & & 6 \\
\hline $\mathrm{A}_{11}$ low carbon expertise & 0.19 & 0.04 & 3 \\
\hline $\mathrm{A}_{12}$ low carbon professional skills & 0.71 & 0.15 & 7 \\
\hline $\mathrm{A}_{13}$ low-carbon innovation potential & 0.10 & 0.02 & 2 \\
\hline $\mathrm{A}_{2}$ work performance & 0.69 & & 1 \\
\hline $\mathrm{A}_{21}$ quantity of completed low-carbon tasks & 0.25 & 0.17 & 4 \\
\hline $\mathrm{A}_{22}$ quality of completed low-carbon tasks & 0.62 & 0.43 & \\
\hline $\mathrm{A}_{23}$ efficiency of completed low-carbon tasks & 0.13 & 0.09 & 9 \\
\hline $\mathrm{A}_{3}$ work attitude & 0.10 & & 5 \\
\hline $\mathrm{A}_{31}$ low-carbon discipline & 0.10 & 0.01 & 7 \\
\hline $\mathrm{A}_{32}$ low-carbon collaboration & 0.70 & 0.07 & \\
\hline $\mathrm{A}_{33}$ low-carbon enthusiasm & 0.20 & 0.02 & \\
\hline
\end{tabular}

\section{Case discussion}

In order to evaluate the performance of low-carbon human resources of logistics Company A, this study additionally invited five senior executives and five professors from A to measure the performances of general employees by using the AHP evaluation indicator method established in this study. A five-point scale is employed to score three evaluation facets and nine indicators. The average score is then calculated, and the weight of each indicator is converted to calculate the actual score. The evaluation results are shown in Table 11.

Table 11

Performance evaluation form of human resources of Company A

\begin{tabular}{|c|c|c|c|c|c|c|}
\hline Dimension & Indicators & $\begin{array}{c}\text { Average } \\
\text { original } \\
\text { score }\end{array}$ & $\begin{array}{c}\text { Order of } \\
\text { average } \\
\text { score }\end{array}$ & $\begin{array}{c}\text { Overall } \\
\text { weight }(G)\end{array}$ & $\begin{array}{c}\text { Overall } \\
\text { weight } \\
\text { order }\end{array}$ & Score \\
\hline \multirow{3}{*}{$\mathrm{A}_{1}$ workability } & $\mathrm{A}_{11}$ low carbon expertise & 3.79 & 4 & 0.04 & 6 & 0.15 \\
\hline & $\begin{array}{l}\mathrm{A}_{12} \text { low carbon professional } \\
\text { skills }\end{array}$ & 3.15 & 7 & 0.15 & 3 & 0.47 \\
\hline & $\begin{array}{c}\mathrm{A}_{13} \text { low-carbon innovation } \\
\text { potential }\end{array}$ & 2.47 & 9 & 0.02 & 7 & 0.05 \\
\hline \multirow{3}{*}{$\begin{array}{c}\mathrm{A}_{2} \text { work } \\
\text { performance }\end{array}$} & $\begin{array}{c}\mathrm{A}_{21} \text { quantity of completed } \\
\text { low-carbon tasks }\end{array}$ & 3.62 & 5 & 0.17 & 2 & 0.62 \\
\hline & $\begin{array}{l}\mathrm{A}_{22} \text { quality of completed } \\
\text { low-carbon tasks }\end{array}$ & 3.12 & 8 & 0.43 & 1 & 1.34 \\
\hline & $\begin{array}{c}\mathrm{A}_{23} \text { efficiency of completed } \\
\text { low-carbon tasks }\end{array}$ & 3.58 & 6 & 0.09 & 4 & 0.32 \\
\hline \multirow{3}{*}{$\mathrm{A}_{3}$ work attitude } & $\mathrm{A}_{31}$ low-carbon discipline & 3.88 & 2 & 0.01 & 9 & 0.04 \\
\hline & $\mathrm{A}_{32}$ low-carbon collaboration & 3.80 & 3 & 0.07 & 5 & 0.27 \\
\hline & $\mathrm{A}_{33}$ low-carbon enthusiasm & 4.13 & 1 & 0.02 & 7 & 0.08 \\
\hline Average & & 3.50 & & & & 3.34 \\
\hline
\end{tabular}

The overall score of Company A is 3.34 points, indicating relatively poor performance of low-carbon human resources. Through our analysis, we see that the main reason is because " $\mathrm{A}_{2}$ work efficiency" takes up a high weight, but exhibits poor performance. The original scores of $\mathrm{A}_{21}$ quantity of completed low-carbon tasks, $\mathrm{A}_{22}$ quality of completed low-carbon tasks, and $\mathrm{A}_{23}$ efficiency of completed low-carbon tasks are relatively low, indicating that the company should improve its quantity, quality, and efficiency of 
low-carbon tasks. In addition, in terms of " $\mathrm{A}_{1}$ work ability", $\mathrm{A}_{12}$ low-carbon professional skills and $\mathrm{A}_{13}$ low-carbon innovation potential are have poor performance. However, $\mathrm{A}_{11}$ low-carbon expertise in " $\mathrm{A}_{1}$ work ability", $\mathrm{A}_{31}$ low-carbon discipline, " $\mathrm{A}_{32}$ low-carbon collaboration", and " $\mathrm{A}_{33}$ low-carbon enthusiasm" in " $\mathrm{A}_{3}$ work attitude" all have excellent performance.

According to the above research results, low-carbon work attitude of employees at Company A in recent years has produced good performance. However, both low-carbon work performance and low-carbon work ability are poor. In this regard, Company A should implement and strengthen these indicators so as to enhance its low-carbon human resources performance.

\section{Conclusions}

In line with the requirements of the current era of low-carbon economies, low-carbon logistics can help effectively address severe social energy consumption and global warming in a bid to achieve sustainable development.

This study establishes a human resources performance evaluation system for low-carbon logistics enterprises to measure the low-carbon working ability, work performance, and working attitude of their general staff. In this way, enterprises may understand their development status, improve development plans, and formulate the best human resources management and development decisions, thus positively guiding their future development.

This study adopts the AHP method to reasonably determine an indicator system of performance evaluation and its weight to avoid certain human-caused bias. According to the research results, the low-carbon work attitude of the case company's general employees in recent years has produced good performance. Moreover, both low-carbon work performance and low-carbon work ability are poor. The case company should proactively implement and strengthen these indicators so as to enhance its human resources performance.

This study not only fills the gap in the related literature, but can also be applied to industrial practice. However, researchers are suggested to select more industries and case companies for a broader discussion of the issues involved. In addition, researchers are suggested to use other evaluation methods for analysis and comparison.

\section{Acknowledgments}

Zhongshan City Science and Technology Bureau Project (No. 2017B1015) and 2018 Zhongshan Innovation and Development Research Center.

\section{References}

[1] Hu Y, Zhou P, Zhou D. What is low-carbon development? A conceptual analysis. Energy Procedia. 2011;(5):1706-10. https://www.sciencedirect.com/science/article/pii/S1876610211012264?via\%3Dihub.

[2] Tsai SB, Yu J, Ma L, Luo F, Zhou J, Chen Q, et al. A study on solving the production process problems of the photovoltaic cell industry. Renew Sust Energy Rev. 2018;82:3546-53. https://www.sciencedirect.com/science/article/pii/S136403211731479X.

[3] Liu B, Li T, Tsai SB. Low carbon strategy analysis of competing supply chains with different power structures. Sustainability. 2017;9:835. DOI:10.3390/su9050835. 
[4] Tsai SB. Using the DEMATEL model to explore the job satisfaction of research and development professionals in China's photovoltaic cell industry. Renew Sust Energy Rev. 2018;81:62-8. https://www.sciencedirect.com/science/article/pii/S1364032117310821.

[5] Raineri A. Linking human resources practices with performance: the simultaneous mediation of collective affective commitment and human capital. Int J Human Resource Manage. 2017;28(22):3149-78. https://www.tandfonline.com/doi/abs/10.1080/09585192.2016.1155163.

[6] Kristen M, Joshua JD, Kyle T, Franz WK. Family firm human resource practices: Investigating the effects of professionalization and bifurcation bias on performance. J Business Res. 2018;84:326-37. https://www.sciencedirect.com/science/article/pii/S0148296317302187.

[7] Daspit JJ, Madison K, Barnett T, Long RG. The emergence of bifurcation bias from unbalanced families: Examining HR practices in the family firm using circumplex theory. Human Resource Manage Rev. 2017;28(1):18-32. https://www.sciencedirect.com/science/article/pii/S1053482217300359.

[8] Ghadimi P, Toosi FG, Heavey C. A multi-agent systems approach for sustainable supplier selection and order allocation in a partnership supply chain. Europ J Operational Res. 2018;269(1):286-301. https://www.sciencedirect.com/science/article/pii/S0377221717306410.

[9] Hosseini S, Sarder MD. Development of a Bayesian network model for optimal site selection of electric vehicle charging station. Int $J$ Electrical Power Energy Systems. 2019;105:110-22. https://www.sciencedirect.com/science/article/pii/S0142061517309936.

[10] Kellner F. Sustainability in supplier selection and order allocation: Combining integer variables with Markowitz portfolio theory. J Cleaner Production. 2019;214:462-74. https://www.sciencedirect.com/science/article/pii/S0959652618340460?via\%3Dihub.

[11] Narayanamoorthy S, Geetha S, Rakkiyappan R, Joo YH. Interval-valued intuitionistic hesitant fuzzy entropy based VIKOR method for industrial robots selection. Expert Systems Applications. 2019;121:28-37. https://www.sciencedirect.com/science/article/pii/S0957417418307772.

[12] Prosman EJ, Sacchi R. New environmental supplier selection criteria for circular supply chains: lessons from a consequential LCA study on waste recovery. J Cleaner Production. 2018;172:2782-92. https://www.sciencedirect.com/science/article/pii/S0959652617328068.

[13] Sinha AK, Anand A. Towards fuzzy preference relationship based on decision making approach to access the performance of suppliers in environmental conscious manufacturing domain. Computers Industrial Eng. 2017;105:39-54. https://www.sciencedirect.com/science/article/pii/S0360835216305113.

[14] Chrisman, JJ, Devaraj S, Patel PC. The impact of incentive compensation on labor productivity in family and nonfamily firms. Family Business Rev. 2017;30(2):119-36. https://journals.sagepub.com/doi/abs/10.1177/0894486517690052.

[15] Saaty TL. The Analytic Hierarchy Process. New York: McGraw-Hill; 1980. ISBN: 0070543712.

[16] Saaty TL. Decision Making with Dependence and Feedback: The Analytic Network Process. Pittsburgh: RWS Publications;1996. ISBN: 1888603070.

[17] Saaty TL, Shih HS. Structures in decision making: On the subjective geometry of hierarchies and networks. European J Operational Res. 2009;199(3),867-72. https://www.sciencedirect.com/science/ article/pii/S0377221709002203.

[18] Sarkis, J. A strategic decision framework for green supply chain management. J Cleaner Production. 2003;11(4):397-409. https://www.sciencedirect.com/science/article/pii/S0959652602000628.

[19] Leung LC, Lam KC, Cao D. Implementing the balanced scorecard using the analytic hierarchy process \& the analytic network process. J Operational Res Soc. 2006;57(6):682-91. https://www.tandfonline.com/ doi/abs/10.1057/palgrave.jors.2602040.

[20] Lan LW, Wu WW, Lee YT. On the decision structures and knowledge discovery for ANP modeling. Int J Intelligence Sci. 2013;3(1A):15-23. DOI: 10.4236/ijis.2013.31A003.

[21] Deng XY, Hu Y, Deng Y, Mahadevan S. Environmental impact assessment impact assessment based on numbers. Expert Systems Applications. 2014;41(2):635-43. https://www.sciencedirect.com/science/ article/pii/S0957417413005897.

[22] Abhishek RD, Sejal SB. Analysis of suitable locations of urban green space based on AHP for Surat City. J Recent Activities Infrastructure Sci. 2017;2(2):1-10. http://matjournals.in/index.php/JoRAIS/ article/view/1533.

[23] Validi S, Bhattacharya A, Byrne PJ. Sustainable distribution system design: a two-phase DoE-guided meta-heuristic solution approach for a three-echelon bi-objective AHP-integrated location-routing model. Annals Operations Res. 2018:1-32. https://link.springer.com/article/10.1007/s10479-018-2887-y.

[24] Huang L. A cultural model of online banking adoption: Long-term orientation perspective. J Organizational End User Computing. 2017;29(1):1-22. DOI: 10.4018/JOEUC.2017010101.

[25] Fabisiak L. Web service usability analysis based on user preferences. J Organizational End User Computing. 2018;30(4):1-13. DOI: 10.4018/JOEUC.2018100101. 
[26] Avdic A. Second order interactive end user development appropriation in the public sector: Application development using spreadsheet programs. J Organizational End User Computing. 2018;30(1):82-106. DOI: 10.4018/JOEUC.2018010105.

[27] Awasthi A, Govindan K, Gold S. Multi-tier sustainable global supplier selection using a fuzzy AHP-VIKOR based approach. Int J Production Economics. 2018;195:106-17. https://www.sciencedirect.com/ science/article/pii/S0925527317303286.

[28] Kalinichenko A, Havrysh V. Environmentally friendly fuel usage: Economic margin of feasibility. Ecol Chem Eng S. 2019;26(2):241-54. DOI: 10.1515/eces-2019-0030.

[29] Awasthi A, Kannan G. Green supplier development program selection using NGT and VIKOR under fuzzy environment. Computers Industrial Eng. 2016;91:100-8. https://www.sciencedirect.com/ science/article/pii/S036083521500457X.

[30] Bavafa A, Mahdiyar A, Marsono AK. Identifying and assessing the critical factors for effective implementation of safety programs in construction projects. Safety Sci. 2018;106:47-56. https://www.sciencedirect.com/science/article/pii/S0925753517309827. 